\title{
Erratum to: Adolescents and young adult cancer survivors: exercise habits, quality of life and physical activity preferences
}

\author{
A. Murnane • K. Gough • K. Thompson • L. Holland • \\ R. Conyers
}

Published online: 25 November 2014

(C) Springer-Verlag Berlin Heidelberg 2014

\section{Erratum to: Support Care Cancer}

DOI 10.1007/s00520-014-2446-2

The original version of this article unfortunately contained mistakes

Physical activity programming preferences and information needs

While most AYA (63 of $74,85 \%$ ) indicated that they would have liked to receive exercise information at some point after their cancer diagnosis, only 41 of 74 (55\%) received such information. Frequent providers of exercise information included medical practitioners ( 21 of $41,51 \%$ ), physiotherapists ( 15 of $41,37 \%$ ), family members (12 of $41,29 \%$ ) and nurses (11 of 41, $27 \%$ ). Nonetheless, most of the participants who would have liked to receive exercise information ( 57 of $63,90 \%$ ) indicated that they would have liked to receive this information from an exercise physiologists (associated with the tertiary centre).

Fifty of 74 participants ( $68 \%$ ) indicated that they would be interested in doing an exercise program aimed at AYA. Of this group, a majority ( 31 of 50, $62 \%$ ) preferred programs starting after treatment. Further, there was a clear preference for home exercise programs ( 34 of 50,68\%) and exercise programs at local gyms ( 25 of $50,50 \%)$ among this group.

The online version of the original article can be found at http://dx.doi.org/ 10.1007/s00520-014-2446-2.

\footnotetext{
A. Murnane $(\bowtie) \cdot K$. Thompson $\cdot$ L. Holland $\cdot$ R. Conyers ONTrac at Peter Mac Victorian Adolescent and Young Adult Cancer Service Peter MacCallum Cancer Centre, Locked Bag 1 A'Beckett St, Melbourne, VIC 8006, Australia e-mail: Andrew.Murnane@petermac.org

K. Gough

Department of Cancer Experiences Research, Peter MacCallum

Cancer Centre, Melbourne, VIC, Australia

R. Conyers

The University of Melbourne, Grattan Street, Parkville, VIC,

Australia

R. Conyers

The Royal Children's Hospital, Parkville, VIC, Australia
} 